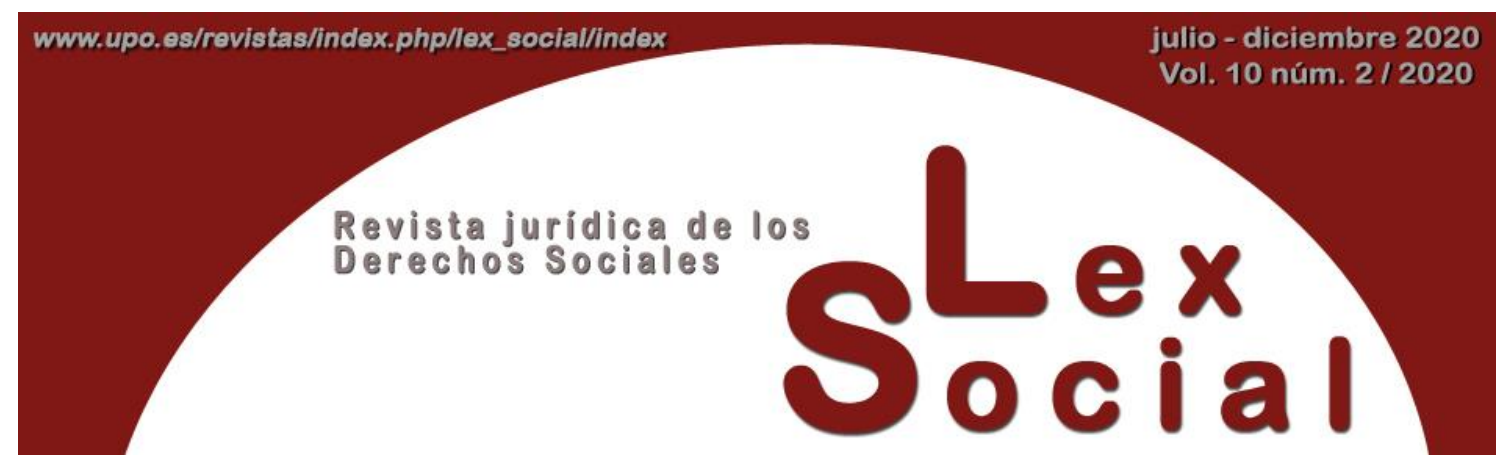

\title{
EL SEGURO POPULAR EN OAXACA Y SU DESAPARICIÓN
}

\section{POPULAR INSURANCE IN OAXACA AND ITS DISAPPEARANCE}

\author{
Dra. SOCORRO MOYADO FLORES \\ Profesora-investigadora \\ Universidad de la Sierra Sur (Oaxaca, México)
}

Artículo recibido el 11 de diciembre de 2019

Artículo aceptado el 12 de febrero de 2020

DOI: $\underline{\text { https://doi.org/10.46661/lexsocial.5081 }}$

\section{RESUMEN}

Este artículo tiene por objetivo analizar la evolución del Seguro Popular en Oaxaca y su desaparición a partir de 2019. Se fundamenta en el planteamiento internacional y nacional sobre el enfoque basado en los derechos humanos que avecina principios claros de no discriminación, disponibilidad y accesibilidad sujeta a la calidad, rendición de cuentas y la universalidad. Se utiliza una metodología cualitativa de alcance descriptivo que busca aportar a la discusión sobre garantizar la salud como derecho social. El sustento jurídico Constitucional mexicano y el reconocimiento de este derecho en la Declaración de los Derechos Humanos y en el Pacto Internacional de los Derechos Económicos, Sociales y Culturales y, junto con otros pactos internacionales que el Estado mexicano ha ratificado, se ha constituido el marco jurídico para su exigibilidad. El estudio se centra en el caso de Oaxaca por tratarse de uno de los estados más pobres de México y el $66 \%$ de su población está afiliada a este seguro.

Palabras Clave: Derechos humanos, seguro popular, pobreza 


\begin{abstract}
This article aims to analyze the evolution of Popular Insurance in Oaxaca and its disappearance from 2019. It is based on the international and national approach to the human rights based approach that approaches clear principles of nondiscrimination, availability and accessibility subject to quality, accountability and universality. A qualitative methodology of descriptive scope is used that seeks to contribute to the discussion about guaranteeing health as a social right. The Mexican Constitutional legal support and recognition of this right in the Declaration of Human Rights and in the International Covenant on Economic, Social and Cultural Rights and, together with other international covenants that the Mexican State has ratified, has established the legal framework for your enforceability. The study focuses on the case of Oaxaca because it is one of the poorest states in Mexico and $66 \%$ of its population is affiliated with this insurance.
\end{abstract}

KEYWORDS: Human rights, popular insurance, poverty.

SUMARIO

1. Introducción.

2. La salud como derecho social.

3. El seguro popular en México.

3.1. Esfuerzos por la universalidad.

3.2. Disponibilidad y accesibilidad.

3.3. Calidad y rendición de cuentas.

4. Oaxaca y el seguro popular.

4.1. Accesibilidad y rendición de cuentas.

4.2. Discriminación.

4.3. Afiliación.

4.4. Disponibilidad.

5. Comentarios finales.

6. Bibliografia.

7. Anexo: normas, informes y estudios.

\title{
1. Introducción.
}

El derecho humano a la salud es parte de los derechos económicos, sociales y culturales, cuya base se encuentra en distintos instrumentos internacionales que el Estado mexicano ha ratificado, a saber: la Declaración de los Derechos Humanos, el Pacto Internacional de 
los Derechos de Económicos, Sociales y Culturales, el Protocolo Adicional a la Convención Americana sobre Derechos Humanos en materia de Derechos Económicos, Sociales y Culturales "Protocolo de San Salvador"; las Convenciones sobre la eliminación de la discriminación racial, sobre la eliminación de la discriminación contra la mujer, y de los derechos del niño, entre otras. Por su parte, la Organización Mundial de la Salud (OMS), afirma en su Constitución que "el goce del grado máximo de salud que se pueda lograr es uno de los derechos fundamentales de todo ser humano." Y "que el derecho a la salud incluye el acceso oportuno, aceptable y asequible a servicios de atención de salud de calidad suficiente". En nuestro país, el artículo $4^{\circ}$, párrafo cuarto, de la Constitución Política de los Estados Mexicanos (CPEUM), así como la Ley General de Salud y su Reglamento en materia de protección social en salud, entre otros instrumentos y normas oficiales, protegen este derecho y lo hacen exigible.

A fin de cumplir con estas disposiciones, en la reforma constitucional de 2003 en materia de salud, se determinó la creación del Sistema de Protección de Servicios de Salud (SPSS) como mecanismo para garantizar el acceso efectivo, oportuno y de calidad para la "población abierta", según su domicilio, esto es, las familias que no cuenten con previsión social en salud o no fuesen derechohabientes de la seguridad social consecuente de una relación laboral, con instituciones como el IMSS, el ISSSTE, Fuerzas Armadas, Marina y PEMEX, principalmente. En 2004 se creó el Seguro Popular como un sistema de financiamiento, para atender los desequilibrios financieros y garantizar un financiamiento justo; enfrentar la segmentación del acceso a la atención a la salud; disminuir los gastos de bolsillo en salud de los hogares mexicanos, y reducir la prevalencia de gastos catastróficos por motivos de salud, así como ofrecer en el futuro un aseguramiento universal.

Mucho se ha escrito respecto a la evolución de los sistemas de salud a nivel internacional y sobre el análisis de costo-beneficio del seguro popular, la aportación en este artículo es la reflexión sobre el alcance de este sistema de financiamiento de gastos catastróficos en México para garantizar la salud como derecho social y comprender si esta política permitió afrontar y corregir desigualdades, prácticas discriminatorias, así como la inequidad para mejorar progresivamente los servicios sanitarios para todas las personas. El estudio se enfoca en la población oaxaqueña afiliada que tiene mayor rezago social y peores índices de pobreza. Se parte del supuesto de que la desaparición del seguro popular a partir de 2019, afectará a Oaxaca si no se logra cumplir con lo expuesto por la Presidencia de la República de sustituirlo con otro esquema más efectivo y eficiente de calidad y de cobertura universal.

Para el análisis, el documento se divide en cinco secciones, incluida esta introducción. En la sección segunda se describe un conjunto de disposiciones normativas internacionales y nacionales que hacen exigible el derecho a la salud; en la tercera se explica el surgimiento del Sistema de Protección Social de Salud (Seguro Popular), sus antecedentes y objetivos generales observando los principios de derechos humanos. En la cuarta sección se analiza la situación actual del caso Oaxaca; y, finalmente como parte de la quinta y última sección se agregan consideraciones adicionales. 


\section{La salud como derecho social.}

Esta sección tiene como propósito describir de forma breve la base del marco jurídico internacional y nacional que permite la exigibilidad de la salud como un derecho humano que forma parte de los derechos económicos, sociales y culturales.

En materia de derechos humanos, México avanzó de forma importante en junio de 2011 cuando se llevó a cabo una de las principales reformas constitucionales al artículo $1^{\circ}$, que establece que todas las personas gozarán de los derechos humanos (entre estos el de la salud), reconocidos en la propia carta magna y en los tratados internacionales de los que el Estado mexicano sea parte, así como de las garantías para su protección, cuyo ejercicio no podrá restringirse ni suspenderse. Se trató, "sin duda alguna, del cambio constitucional en materia de derechos básicos más importante del último siglo, que representa un nuevo paradigma para el respeto, protección, garantía y satisfacción de los derechos humanos" (Carmona Tinoco, 2011, p.39).

Como parte de estos derechos, en la última década se ha discutido en el ámbito académico y político si los derechos económicos, sociales y culturales (DESC), como la salud, son susceptibles de exigencia en la esfera judicial; o bien quedan a expensa sólo de los presupuestos públicos aprobados en el poder legislativo y ejercidos por el ejecutivo, respectivamente. Esta discusión ha llevado al enfoque basado de derechos, que asume que el Estado tiene la responsabilidad de respetar, proteger, garantizar y promover los DESC, al diseñar el marco normativo e institucional para proveer de los bienes y servicios que permitan las condiciones mínimas de disponibilidad, accesibilidad y calidad de los derechos.

En lo anterior, la Organización Mundial de la Salud (OMS, 2017) mantiene su liderazgo técnico, intelectual y político en relación con el derecho a la salud, por lo que fortalece su capacidad y la de sus Estados Miembros en la adopción de un enfoque basado en derechos. Un enfoque de la salud basado en los derechos humanos, toma en cuenta principios claros para implementar y evaluar las políticas de salud y la prestación de servicios, corrigiendo prácticas discriminatorias y relaciones de poder injustas que generan inequidad. Con este enfoque; las políticas, estrategias y programas de salud deben diseñarse explícitamente para mejorar el disfrute de todas personas con derecho a la salud, considerando a los más rezagados primero. Los principios y estándares básicos de este enfoque son los siguientes:

$\checkmark$ No discriminación: el principio de no discriminación procura garantizar el ejercicio de los derechos sin discriminación alguna por motivos de raza, color, sexo, idioma, religión, opinión política o de otra índole, origen nacional o social, posición económica, nacimiento o cualquier otra condición, por ejemplo, discapacidad, edad, estado civil y familiar, orientación e identidad sexual, estado de salud, lugar de residencia y situación económica y social (Committee on Economic, 2009).

$\checkmark$ Disponibilidad: se deberá contar con un número suficiente de establecimientos, bienes y servicios públicos de salud, así como de programas de salud. 
$\checkmark$ Accesibilidad: los establecimientos, bienes y servicios de salud deben ser accesibles a todos. La accesibilidad presenta cuatro dimensiones superpuestas:

- Aceptabilidad: todos los establecimientos, bienes y servicios de salud deberán ser respetuosos de la ética médica y culturalmente apropiados, y sensibles a las necesidades propias de cada sexo y del ciclo vital.

- Calidad: los establecimientos, bienes y servicios de salud deberán ser apropiados desde el punto de vista científico y médico y ser de buena calidad.

- Rendición de cuentas: los Estados y otros garantes de los derechos son responsables de la observancia de los derechos humanos.

- Universalidad: los derechos humanos son universales e inalienables. Todas las personas, en cualquier lugar del mundo, deben poder ejercerlos.

Este rumbo posibilita el tránsito de lo entendido como derecho subjetivo a la materialización de éste mediante acciones institucionales concretas (CONEVAL, 2018), lo que refuerza la exigibilidad.

En el contexto internacional, la Declaración de los Derechos Humanos de 1948 en su artículo 25 establece en la fracción " 1 . Toda persona tiene derecho a un nivel de vida adecuado que le asegure, así como a su familia, la salud y el bienestar, y en especial la alimentación, el vestido, la vivienda, la asistencia médica y los servicios sociales necesarios..." Por su parte, el Pacto Internacional de los Derechos de Económicos, Sociales y Culturales de 1966 en el artículo 12, fracción 1, se estipula que "Los estados partes en el presente Pacto reconocen el derecho de toda persona al disfrute del más alto nivel posible de salud física, mental y social”.

A nivel regional, el Protocolo Adicional a la Convención Americana sobre Derechos Humanos en materia de Derechos Económicos, Sociales y Culturales "Protocolo de San Salvador" de 1988, en su artículo 10 fracción 1, reproduce esta definición: "Toda persona tiene derecho a la salud, entendida como el disfrute del más alto nivel de bienestar físico, mental y social". En las Convenciones sobre la Eliminación de la Discriminación Racial, sobre la Eliminación de la Discriminación contra la Mujer (CEDCM) y respecto de los Derechos del Niño (CDN), también se determina el derecho a la protección de la salud, la no discriminación para recibirla y, a la seguridad en las condiciones de trabajo, incluso la garantía de la función de reproducción en el caso de la mujer y su bienestar social, espiritual y moral y su salud física y mental, en el caso de la niñez.

Es importante aclarar que existen adicionalmente otros instrumentos internacionales que soportan el derecho a la salud, así como compromisos muy concretos como los objetivos del Milenio del año 2000 y ahora los Objetivos de Desarrollo Sostenible 2030, de los cuales el tercero está relacionado a la salud y el bienestar, y que todos los Estados Miembros adoptaron en 2015. 
El Estado mexicano ha ratificado los distintos pactos internacionales por lo que en el régimen doméstico se asumen estas disposiciones en la CPEUM, en el artículo $4^{\circ}$, párrafo cuarto: "Toda persona tiene derecho a la protección de la salud. La Ley definirá las bases y modalidades para el acceso a los servicios de salud y establecerá la concurrencia de la Federación y las entidades federativas en materia de salubridad general..." En la Ley General de Salud (LGS), artículo $1^{\circ}$. Bis, se entiende la salud "como un estado de completo bienestar físico, mental y social, y no solamente la ausencia de afecciones o enfermedades".

Asimismo, en el artículo 77 bis 1 de la misma Ley se instituye el principio de no discriminación:

"...todos los mexicanos tienen derecho a ser incorporados al Sistema de Protección Social en Salud (SPSS) mecanismo que "garantizará el acceso efectivo, oportuno, de calidad, sin desembolso al momento de utilización y sin discriminación a los servicios médicoquirúrgicos, farmacéuticos y hospitalarios que satisfagan de manera integral las necesidades de salud, mediante la combinación de intervenciones de promoción de la salud, prevención, diagnóstico, tratamiento y de rehabilitación, seleccionadas en forma prioritaria según criterios de seguridad, eficacia, costo, efectividad, adherencia a normas éticas profesionales y aceptabilidad social”.

El artículo 77 bis 26 y el 77 bis 30, respectivamente; el primero indica que "el nivel de ingreso o la carencia de éste, no podrán ser limitantes para el acceso al Sistema de Protección Social en Salud", y el segundo establece que:

... Con el objetivo de fortalecer la infraestructura médica de alta especialidad y su acceso o disponibilidad regional, la Secretaría de Salud, mediante un estudio técnico, determinará aquellas unidades médicas de las dependencias y entidades de la administración pública, tanto federal como local, que por sus características y ubicación puedan ser reconocidos como centros regionales de alta especialidad o la construcción con recursos públicos de nueva infraestructura con el mismo propósito, que provean sus servicios en las zonas que determine la propia dependencia.

Estas premisas se refuerzan en el Reglamento correspondiente y otras normas oficiales, los cuales son instrumentos para que el Estado conduzca las acciones concretas con el fin de garantizar este derecho, coordinando las acciones con las entidades federativas del país, así como su financiamiento. Asimismo, el Programa Sectorial de Salud 2013-2018 señala, en su objetivo 5 y su Estrategia 5.2 "Impulsar la eficiencia del uso de los recursos para mejorar el acceso efectivo a servicios de salud con calidad", a fin de mejorar la transparencia, monitoreo y control de los recursos financieros del seguro popular y realizar los ajustes operativos necesarios a dicho sistema.

Sin embargo, aun cuando este entramado institucional fundamenta la exigibilidad del derecho a la salud, y el Estado mexicano ha ratificado los distintos pactos internacionales, existen restricciones políticas, presupuestales y de gestión para poner en práctica el enfoque de derechos humanos que corrija la discriminación, disponibilidad y 
accesibilidad, esto es, lograr la cobertura universal de calidad como se observa en adelante.

\section{El seguro popular en México.}

En esta sección se explican brevemente las acciones cronológicas que se implementaron para el surgimiento del seguro popular en México como un sistema de financiamiento de gastos catastróficos, que pretendió garantizar el acceso universal, corregir desigualdades y prácticas discriminatorias al concentrarse en la población abierta más desprotegida económicamente. Se describen al mismo tiempo desde el enfoque de derechos humanos, algunos aspectos de disponibilidad y accesibilidad y sus dimensiones de calidad y rendición de cuentas en materia de salud.

\subsection{Esfuerzos por la universalidad.}

De las últimas décadas del XX a la fecha, en el mundo, el desarrollo de los sistemas de salud han presentado retos importantes para garantizar el enfoque de los derechos humanos, la cobertura del aseguramiento universal de la población, la calidad de los servicios y principalmente su financiamiento. Desde una visión ética, el modelo canadiense considera a la salud como un bien social, que debe estar a disposición de todos los miembros de la sociedad, bajo los mismos términos de acceso, financiamiento y calidad. La mayoría de los sistemas de países de Europa Occidental conciben a la salud también como un bien social para la mayoría de la población, aunque, permitiendo que los grupos sociales con mayores recursos económicos adquieran cobertura complementaria. Con una postura más de mercado, en Estados Unidos la salud es vista como un bien privado, lo cual lleva a que el acceso, el financiamiento y la calidad de este bien varíe conforme al nivel socioeconómico de los integrantes de la sociedad (SS y SP, 2005:15)

En América Latina y el Caribe existe una combinación de los anteriores, ya que la mayor parte de los sistemas latinoamericanos de salud están compuestos por tres subsistemas; seguridad social, los servicios públicos y los privados con distintos grados de desarrollo, según el país del que se trate (OIT-OPS, 1999), (Cano, 2010). En la mayoría de estos países el derecho a la protección de la salud se reconoce constitucionalmente; esto significa que éticamente es inaceptable que la persona que enferme no pueda atenderse por falta de recursos y pueda morir o quedar discapacitado (Laurell, 2013).

En el estudio de la OIT-OPS, se presenta la clasificación de los sistemas, conforme a su cobertura de seguridad social y su integración, referida ésta última con el grado de articulación entre subsistemas; por ejemplo: Chile, Colombia, Costa Rica y países de la subregión Caribe no Latino, han adoptado sistemas más parecidos al sistema inglés con elevada cobertura e integración. México aparece en el grupo 3, junto con Argentina, Paraguay y Venezuela con elevada cobertura y baja integración, son países en los que existen diferencias de cobertura entre distintos grupos poblacionales (OIT-OPS, 
1999:13). La estructura de desigualdad social que predomina en los países latinoamericanos ha sido esencial para no garantizar el derecho a la salud de forma equitativa y entre los excluidos se encuentran "los pobres, los adultos mayores, las mujeres, los niños, los grupos indígenas, los trabajadores no asalariados, los trabajadores de la economía informal, los desempleados, los subempleados, así como la población rural" (SS-SP, 2005 p. 16). Contrario al enfoque derechos humanos.

Por presiones externas y por las propias condiciones internas, el Estado mexicano ha buscado distintas opciones para compartir con el sector privado esta responsabilidad y poder ofrecer el aseguramiento médico universal. Al respecto, Laurell (2013:36) plantea que las reformas en salud (1983, 2003 y 2007) en nuestro país, están inscritas en el ajuste y cambio estructural neoclásico-neoliberal distinguido por su segmentación y fragmentación entre las instituciones del sistema de salud, aunque se declare el aseguramiento universal con portabilidad de los seguros, incluyendo los privados.

De hecho, desde 1943 en México el sistema de salud surgió dividido al separar a la población entre aquellos que tenían derechos sociales bien definidos que se integraban al naciente Instituto Mexicano del Seguro Social (IMSS) (derechohabientes), y aquellos que eran sujetos de la asistencia del Estado, a quienes se les reconoció desde entonces como población abierta, atendida por la Secretaría de Salubridad y Asistencia, ahora Secretaría de Salud (desde 1982). El sistema de los derechohabientes se fortalece en 1960 con la creación del Instituto de Seguridad y Servicios Sociales de los Trabajadores del Estado (ISSSTE), el cual se suma otras instituciones que venían atendiendo a los asegurados, como el Instituto de Seguridad Social para las Fuerzas Armadas Mexicanas (1917), al sistema de Salud Naval (1939) y a los servicios de salud de Petróleos Mexicanos (19381940) entre los más importantes.

Por su parte la población abierta, continuó recibiendo los servicios de salud como asistencia social, y no como un derecho, es hasta los años dos mil que en el Plan Nacional de Desarrollo 2001-2006, se planteó como uno de los objetivos “Ofrecer protección financiera en materia de salud a todos los mexicanos, apoyando de manera prioritaria el financiamiento público, y con mayor detalle se propuso como Estrategia 5 del Programa Nacional de Salud de esa administración "Brindar protección financiera en materia de salud a toda la población”, mediante 1) La consolidación de la protección básica de todos los mexicanos y la creación de un seguro de salud popular universal, equitativo y que garantice calidad en los servicios cubiertos. 2) La ampliación de la afiliación al seguro social, y 3) el reordenamiento y la regulación de los seguros privados. Con esta estrategia se postulaba que "El concepto de población abierta podrá entonces desecharse, ya que todos los mexicanos tendrán la categoría de derechohabiente" (SS, 2001). Esta fue la visión equivocada de considerar que con sólo la afiliación se estaba atendiendo a la salud con enfoque de derechos humanos y se avalaba la cobertura universal.

Es así que en marzo de 2002 la SS publica en el Diario Oficial de la Federación las reglas de operación e indicadores de gestión y evaluación del Seguro Popular de Salud. Estas reglas se fortalecen en mayo de 2003 con la publicación del decreto por el que se reforma 
y adiciona la Ley General de Salud (LGS) para crear el Sistema de Protección Social en Salud (SPSS) e inicia en 2004 la operación formal del Seguro Popular (SP). En el artículo 75, bis 35 de la LGS se establece que el SPSS, contará con una Comisión Nacional de Protección Social en Salud (CNPSS) como órgano desconcentrado de la SS, y esta institución planteó que este Seguro es "seguro", porque otorga a las familias la seguridad de saber que si llega a enfermar alguno de sus miembros no tendrán que preocuparse sobre cómo pagar la atención y los medicamentos; y es "popular", porque va dirigido al pueblo, a las familias más pobres, a todas las personas que trabajan por cuenta propia y que, por tanto, no están cubiertas por alguna institución de seguridad social (Frenk, 2018), (CNPSS, s/f).

Sin embargo, la LGS todavía presenta restricciones para la universalidad como la observada en el artículo 77 bis 39, que establece que los servicios pueden suspenderse temporalmente si el afiliado no paga anticipadamente la cuota familiar respectiva, desprotegiendo eventualmente a las familias.

La cobertura universal ha sido mal entendida, al apostar sólo al masivo registro o afiliación, y no a garantizar que todas las personas cuenten con acceso efectivo a los servicios de salud que requieren (Delgado, 2019). Además, para la accesibilidad, el gasto de bolsillo nacional constituye $45 \%$ de los ingresos del sistema de salud y $4.0 \%$ del gasto de los hogares (OCDE, 2016), lo que significa que quien puede pagar lo hace y quien no, asume las consecuencias desastrosas.

\subsection{Disponibilidad y accesibilidad.}

Los principales objetivos del seguro popular han sido: a) Atender los desequilibrios financieros y garantizar un financiamiento justo; b) Hacer frente a la segmentación del acceso a la atención a la salud; c) Disminuir la proporción de gastos de bolsillo en salud de los hogares mexicanos, y d) Reducir la prevalencia de gastos catastróficos por motivos de salud e incrementar la cobertura del aseguramiento en salud (Delgado, 2019).

Sin embargo, los presupuestos son restricciones significativas para la disponibilidad, en México, la salud cuenta con menos recursos que otros países de la OCDE; el país destinó el 5.5\% del PIB a la salud en 2017, mientras que el promedio en la Organización fue de 8.9\% (OCDE, 2016), lo que conlleva a la menor inversión en establecimientos, bienes y servicios públicos de salud.

En 2002 se llevó a cabo una prueba piloto del seguro en el que participaron cinco estados: Campeche, Tabasco, Jalisco, Aguascalientes y Colima, pero se firmaron convenios hasta 2003, durante 2004 se incorporaron 21 entidades más, entre éstas Oaxaca. Chihuahua, Durango y el Distrito Federal fueron los últimos en iniciar operaciones en 2005. En la estructura del federalismo mexicano, los estados quedaron como responsables a nivel local de la afiliación de beneficiarios, administración de recursos, supervisión de los prestadores de servicios y pagos de los mismos. 
A 15 años de su creación, el padrón del seguro popular creció en forma significativa al pasar de 5.3 millones en 2004 a 51.4 millones de afiliados a junio de 2019 en toda la República mexicana, lo que implica el $41 \%$ de la población total. Aunque, debido a que la meta anual de afiliación se determina con base en la disponibilidad presupuestaria, de 2016 a 2019 la afiliación disminuyó (Figura 1). Es así que la falta de presupuestos suficientes para la salud, representa una acción concreta que las autoridades utilizan como justificación para el incumplimiento de disponibilidad; bienes y servicios de salud suficientes; sin plantearse que muchos de los recursos son desviados a otras acciones o mal administrados hasta convertirse en actos de corrupción.

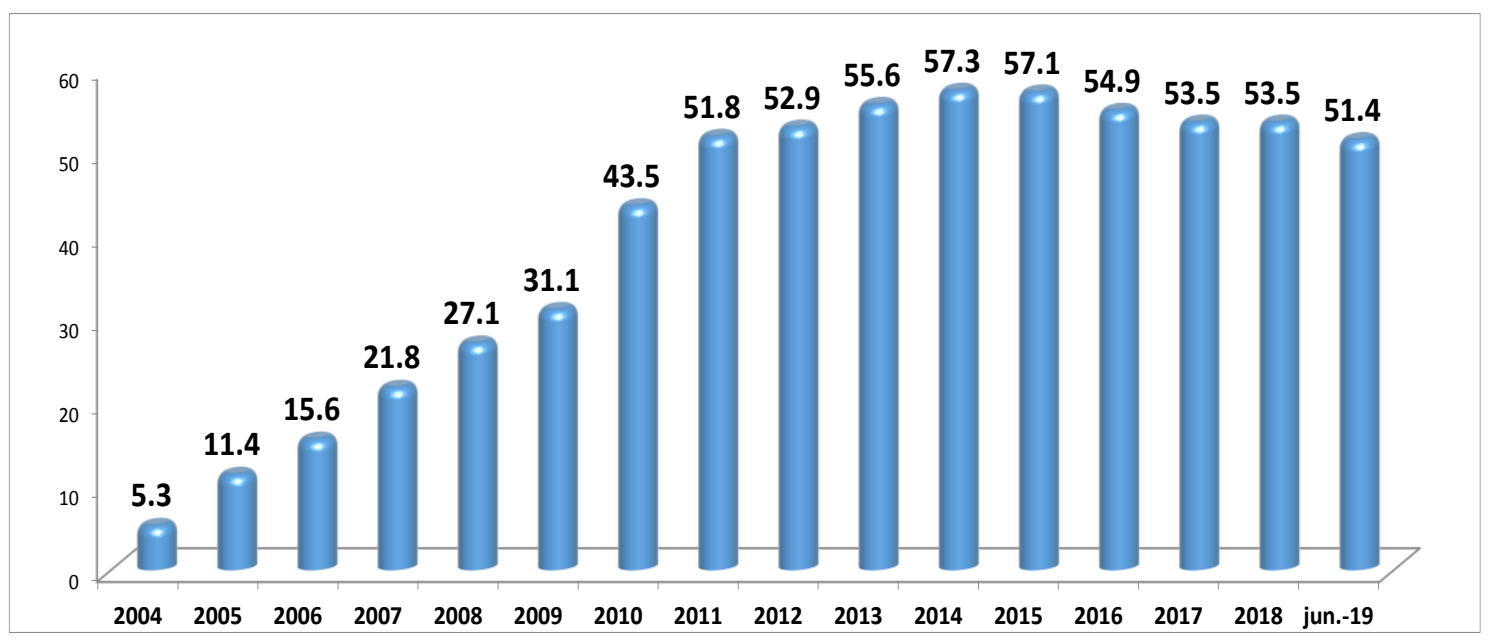

Figura 1. Afiliación acumulada de 2004 a junio de 2019. Fuente: Comisión Nacional de Protección Social en Salud, 2019.

En los datos de la figura 1 se incluye el Seguro Médico para una Nueva Generación, decretado en 2007, cuyo objetivo ha sido contribuir a la disminución del empobrecimiento por motivo de salud, a través del aseguramiento médico universal de los niños menores de cinco años de edad, sin seguridad social y nacidos a partir del $1^{\circ}$ de diciembre de 2006, posteriormente en 2013 se transformó en Seguro Médico Siglo XXI, y en 2019, suman 4.5 millones de niños incluidos (CNPSS, 2019). Según estos datos, la afiliación total acumulada al cierre de junio de 2019 (51.4 millones), representa el 96\% con respecto a la cobertura programada acumulada anual.

Si se toma en cuenta que en 2018 se registran 71.7 millones de personas (57.3\%) con carencia de acceso a la seguridad social, más que en 2016 (55.8\%) (CONEVAL, 2019), el seguro popular no ha cumplido el derecho a la salud establecido en el artículo octavo transitorio de la LGS de 2003, que determinó que en 2010 se incorporaría el 100\% de las familias susceptibles; esto es, se ha dejado de hacer lo que se consideraba posible por omisión. En cuanto al acceso a los servicios de salud, la cobertura universal tampoco se cumple al permanecer con esta carencia 20.2 millones de personas (16.2\%), más que en 2016 (15.5\%), lo que podría utilizarse como justificación para su desaparición.

Lo mismo sucede con los servicios y medicamentos, en 2002 se aplica el Catálogo de Beneficios Médicos (CABEME) con 78 intervenciones y 165 medicamentos, en 2004 
éste se convirtió en Catálogo de Servicios (CASES) con 91 intervenciones y 168 medicamentos y en 2013 se transformó en Catálogo Universal de Servicios de Salud (CAUSES) y se incrementaron las intervenciones hasta en 294, agrupadas en 5 conglomerados: Prevención y promoción en salud (27 intervenciones); medicina general y de especialidad (120); Urgencias (69); Cirugía general (54); Obstetricia (24). Esto representaría la cobertura en la totalidad de las intervenciones del primer nivel de atención médica y los principales padecimientos reportados como egresos hospitalarios; así como en 61 intervenciones consideradas como catastróficas por su complejidad y alto costo, financiadas por el Fondo de Protección Contra Gastos Catastróficos (FPGC) (CNPSS, 2018).

No obstante, el incumplimiento se debe al grave problema de la inexistencia de infraestructura, equipamiento y suministros suficientes (centros de salud y hospitales, equipos y materiales o bien medicamentos) sobre todo en el ámbito rural, que ha limitado la posibilidad de brindar con la calidad y oportunidad requerida los servicios, lo que hace que las pólizas de los afiliados, se conviertan en letra muerta en las emergencias. Las autoridades de los tres órdenes de gobierno saben de estas limitaciones y aun así dejan de hacer lo que es posible, administrar eficaz y eficientemente los recursos, cayendo en omisiones que deben ser juzgadas conforme al enfoque de derechos, en virtud de que estas omisiones podrían derivarse del desvío de recursos (rendición de cuentas) que debieron aplicarse en el campo sanitario y que podrían haberse utilizado para otras acciones, en varios casos vinculados a actos políticos o de uso indebido de los recursos públicos.

La accesibilidad también se ha discutido, de las 294 intervenciones que constituyen 1,807 enfermedades cubiertas, representan sólo el 14.2\% de cobertura, comparadas con las 12,643 claves totales de enfermedades existentes en la Clasificación Estadística Internacional de Enfermedades y Problemas Relacionados con la Salud (CIE-10). Lo mismo pasa con los medicamentos asociados a las intervenciones cubiertas por el CAUSES, ya que, de las 1,815 claves de medicamentos del Cuadro Básico y Catálogo de Medicamentos vigente, publicado por el Consejo de Salubridad General, únicamente se consideran 633 claves de medicamentos y 37 insumos médicos, lo que representa el $34.8 \%$ de cobertura, ello implica un gasto de bolsillo para la población, ya sea por no estar afiliado o porque su afiliación no cubre su padecimiento (CNPSS, 2019).

Como el seguro popular más que un modelo de atención a la salud, es un sistema de financiamiento, se integra por recursos que asignan la federación, las entidades federativas y cuotas de los beneficiarios; esto significa que los tres órdenes de gobierno debieran garantizar el derecho y su rendición de cuentas. La aportación gubernamental inició en 2002 con un subsidio per cápita de 398.00 y familiar de 1,751, considerando 4.4 miembros por familia, en 2018 la aportación ascendió en promedio anual a 3,335.48 pesos por afiliado, sumando las aportaciones federales y estatales (CNPSS, 2019) (Figura 2). Estas aportaciones se regulan con base a lo establecido en los artículos 77 bis 12 y 13 de la LGS. De éstos la Secretaría de Salud canalizará anualmente el $8 \%$ al Fondo de Protección contra Gastos Catastróficos, artículo 77 bis 17 de misma LGS 


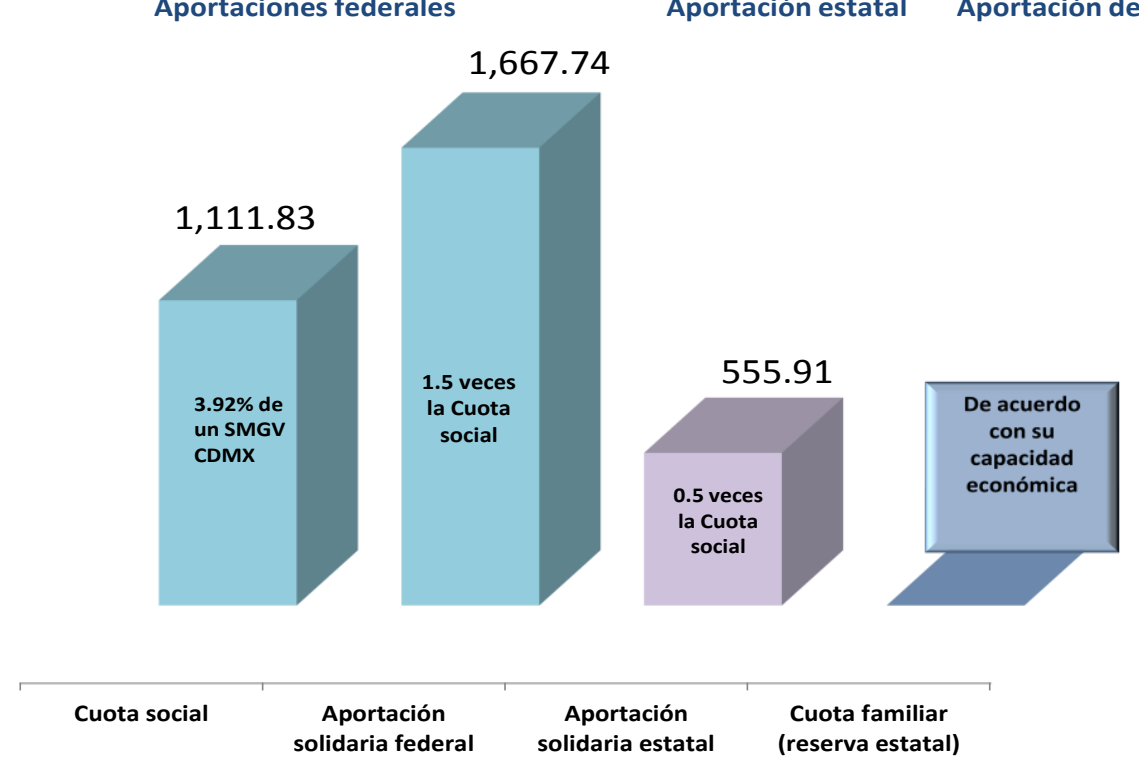

Figura 2. Financiamiento del Seguro Popular. Fuente: Informe de resultados de la CNPSS, 2019.

Por su parte, las cuotas de aportación por familia se modificaron durante los primeros cinco años, conforme a lo establecido en la LGS y a las disposiciones reglamentarias, pero a partir de 2008, han permanecido igual entre los deciles de ingreso del V a X (tabla 1).

\begin{tabular}{cccccc}
\hline $\begin{array}{c}\text { Decil de } \\
\text { ingreso }\end{array}$ & 2002 a 2003 & 2004 y 2006 & 2007 & 2008 a 2010 & 2011 a 2018 \\
\hline I & 240.00 & 0 & 0 & 0 & 0 \\
II & 360.00 & 0 & 0 & 0 & 0 \\
III & 600.00 & 640.00 & 688.09 & 713.96 & 0 \\
IV & $1,080.00$ & $1,255.00$ & $1,349.31$ & $1,400.04$ & 0 \\
V & $1,800.00$ & $1,860.00$ & $1,999.78$ & $2,074.97$ & $2,074.97$ \\
VI & $2,280.00$ & $2,540.00$ & $2,730.88$ & $2,833.56$ & $2,833.56$ \\
VII & $3,000.00$ & $3,270.00$ & $3,515.74$ & $3,647.93$ & $3,647.93$ \\
VIII & $3,600.00$ & $5,065.00$ & $5,445.62$ & $5,650.38$ & $5,650.38$ \\
IX & $4,800.00$ & $6,740.00$ & $7,246.50$ & $7,518.97$ & $7,518.97$ \\
X & $6,000.00$ & $10,200.00$ & $10,966.52$ & $11,378.86$ & $11,378.86$ \\
\hline
\end{tabular}

Tabla 1. Cuotas por familia anuales. Fuente: CNPSS. Aviso publicado en el DOF del año respectivo, así como los Lineamientos para la afiliación, operación, integración del padrón nacional de beneficiarios y determinación de la cuota familiar del SPSS de cada año.

El ingreso familiar se determina a partir de la evaluación socioeconómica de cada familia que se realiza en el momento de la afiliación, y así se les clasifica en los distintos deciles. Durante los primeros años de la operación SPSS, se trató de familias de localidades semiurbanas y urbanas de los seis primeros deciles, sin considerar los índices de 
marginación, aunque la LGS establecía que se daría prioridad a la población de los dos primeros deciles ingreso de áreas de mayor marginación, zonas rurales e indígenas.

Más tarde, son parte del régimen no contributivo las familias de los deciles I, II, III y IV, así como las ubicadas en los deciles I al VII que tengan al menos un niño mexicano nacido al momento de incorporarse al SPSS o que cuenten con una mujer embarazada. Adicionalmente, se podrán considerar sujetos de incorporación a dicho régimen aquellas familias que sean beneficiarias de los programas de combate a la pobreza extrema del gobierno federal, residentes en localidades rurales; residentes en localidades de muy alta marginación con menos de doscientos cincuenta habitantes; y, las que determinara la CNPSS o las entidades federativas, conforme a sus competencias, según la LGS y el Reglamento.

\subsection{Calidad y rendición de cuentas.}

La calidad de la atención es el grado en que los servicios de salud para personas y poblaciones incrementan la probabilidad de resultados de salud deseados y son consistentes con el conocimiento profesional actual. Son siete las características con las que deberían cumplir estos servicios: eficacia, seguridad, centrado en las personas, oportunidad, equidad integrados y eficientes (World Health Organization, 2018).

Al no ser un modelo de atención, sino un esquema de financiamiento, en el Seguro Popular el interés se pone en financiar la enfermedad y no en brindar a la población el acceso oportuno, de calidad y equitativo a los servicios de acuerdo con sus necesidades, con equilibrio entre la prevención, promoción y educación de la salud, por lo que no se garantiza la mejora de la salud de los afiliados, ni se consigue que este derecho se afronte de manera integral y entre todas las instituciones involucradas.

Se derrocharon muchos recursos, abandonando diversas obras e infraestructura a nivel nacional, así como erogando recursos extraordinarios en la compra de medicamentos. Por ejemplo, a bien de optimizar gastos en el gobierno, se detectaron diferencias significativas hasta de 358 millones de pesos en 2016, entre el IMSS y el seguro popular, en los precios de compra y en el tipo de insulina para pacientes de diabetes, ya que este último compró a precios más altos y en mayor proporción insulinas de patente, y en el caso el IMSS se siguió la recomendación de la OMS de procurar insulinas de precios bajos (Hernández, et.al, 2018).

Los actos de corrupción y falta de rendición de cuentas disminuyeron de manera significativa los recursos financieros disponibles, lo que impactó negativamente en el acceso a la atención médica, inhibiendo el crecimiento de la infraestructura física disponible y dificultando de forma importante su mantenimiento en condiciones óptimas, comprometiendo la calidad de la atención médica (Hernández, et.al, 2018).

Por ello, a partir de una visión de rendición de cuentas, el actual presidente de la República Andrés Manuel López Obrador "anunció la creación del Instituto de Salud para el Bienestar, con lo que se dará fin al Seguro Popular. Informó que para la nueva instancia 
se destinarán alrededor de 80 mil millones de pesos del Fondo de Protección contra Gastos Catastróficos" (Muñoz, 2019).

En ese sentido, la nueva gestión pública (2018-2024) del Sistema Protección de Servicios de Salud (SPSS) ha planteado que durante el primer semestre de 2019, enfatizó en la revisión de algunas omisiones y rezagos encontrados al inicio del actual gobierno, como la falta de apego a las condiciones de calidad de los establecimientos de salud, la depuración de la cartera del Fondo de Protección contra Gastos Catastróficos (FPGC), entendidos estos gastos como aquellos que según el artículo 77 bis 29 de la LGS señala...

...se derivan de tratamientos y medicamentos asociados, definidos por el Consejo de Salubridad General, que satisfagan las necesidades de salud mediante la combinación de intervenciones de tipo preventivo, diagnóstico, terapéutico, paliativo y de rehabilitación, con criterios explícitos de carácter clínico y epidemiológico, seleccionadas con base en su seguridad, eficacia, costo, efectividad, adherencia a normas éticas profesionales y aceptabilidad social, que impliquen un alto costo en virtud de su grado de complejidad o especialidad y el nivel o frecuencia con la que ocurren (DOF, 2018).

Se pretende con la depuración del Fondo, la liberación de recursos para incorporar otras intervenciones y financiar las obras de infraestructura inconclusas, así como su ampliación, colaborando también con el Consejo de Salubridad General en el cotejo del padrón de beneficiarios, determinando las afiliaciones duplicadas con otros regímenes de seguridad social, y buscando abrir espacios de afiliación a personas excluidas en el sistema (CNPSS, 2019).

En la iniciativa de Ley se establece que respecto al financiamiento de los servicios, las transferencias del gobierno federal a los estados se mantiene, en el proyecto de presupuesto de egresos de la federación para 2020, todavía se dejó al seguro popular la cantidad de \$36,082,175,529 pesos del Ramo 12 Administrativo de la Secretaría de Salud, pero se refuerza la regulación por parte de esta Secretaría para "vigilar y fiscalizar el uso transparente y eficiente de los recursos transferidos, e introduce la evaluación sistemática del cumplimiento de la nueva política en los aspectos de accesibilidad, calidad, oportunidad e integralidad de los servicios prestados" (Delgado, 2019).

No obstante, lo anterior no determina ni eficacia, ni eficiencia, ni equidad o el servicio centrado en la personas, la lentitud de los procesos ha sido cuestionado porque los pacientes de las distintas enfermedades son los que han sufrido esta transición, violentándose el artículo 77 bis 36 de la citada LGS, que indica que los beneficiarios del SPSS "tienen derecho a recibir bajo ningún tipo de discriminación, los servicios de salud, los medicamentos y los insumos esenciales requeridos para el diagnóstico y tratamiento de los padecimientos, en las unidades médicas de la administración pública, tanto federal como local, acreditados de su elección de los Regímenes Estatales de Protección Social en Salud".

Por ello los cuestionamientos de quienes diseñaron o estuvieron al frente en distintos momentos del sistema, se considera que la reforma anunciada carece de competencia técnica, un bajo desinterés por la transparencia y rendición de cuentas, atado a 
negociaciones políticas, falto de reglas operativas y centralizado. Según Julio Frenk "el camino es claro: construir sobre los aciertos del seguro popular y superar sus indiscutibles limitaciones es una mejor opción que su destrucción irreflexiva” (Frenk, 2019).

Por su parte Alejandro Moreno (2019), quien ha realizado mediciones constantes sobre el actuar del gobierno. La cancelación del seguro popular no es bien vista por los ciudadanos, el $75 \%$ considera desfavorable esta decisión. En este sentido, cabe preguntarse ¿cómo afecta esta situación en entidades cuya población depende en gran medida de esta política pública? Como es el caso de Oaxaca.

\section{Oaxaca y el seguro popular}

Esta sección se centra en el análisis de Oaxaca, uno de los estados de la República mexicana con muy alto grado e índice de rezago social (2.539013), ubicado al sureste del país con 570 municipios, cuyas condiciones socioeconómicas hacen extraordinariamente vulnerable a su población para afrontar gastos catastróficos relacionados con diversas enfermedades.

\subsection{Accesibilidad y rendición de cuentas}

Como se ha indicado el principio, accesibilidad implica que los establecimientos, bienes y servicios de salud deben estar al alcance de toda la población. Sin embargo, también se ha dicho que los presupuestos son una restricción considerable y más aún cuando los recursos son mal utilizados y existe opacidad en su manejo y destino y no existe la rendición de cuentas financiera, menos aún la responsabilidad de la observancia de derechos humanos por parte de las autoridades.

En 2017 el gasto público total en salud a nivel nacional fue de $\$ 622,937,399$ miles de pesos corrientes, junto con una cantidad similar de gasto privado $(\$ 586,357,172$ que comprende gasto de los hogares, cuotas de recuperación y pago de primas), en Oaxaca durante el mismo año, el gasto público ascendió a \$15, 858,630 miles de pesos, de los cuales al gobierno estatal corresponde tan sólo el .5\% ( $\$ 72,573$ miles de pesos). El gasto del estado representa el $2.5 \%$ del gasto público total nacional de ese año, proporción que se ha mantenido durante los últimos dos sexenios. El mayor porcentaje de gasto se hace en el Distrito Federal (ahora Ciudad de México) y en el estado de México, los cuales van entre $16 \%$ el primero y $12 \%$ el segundo en relación con el del total nacional (Figura 3). 


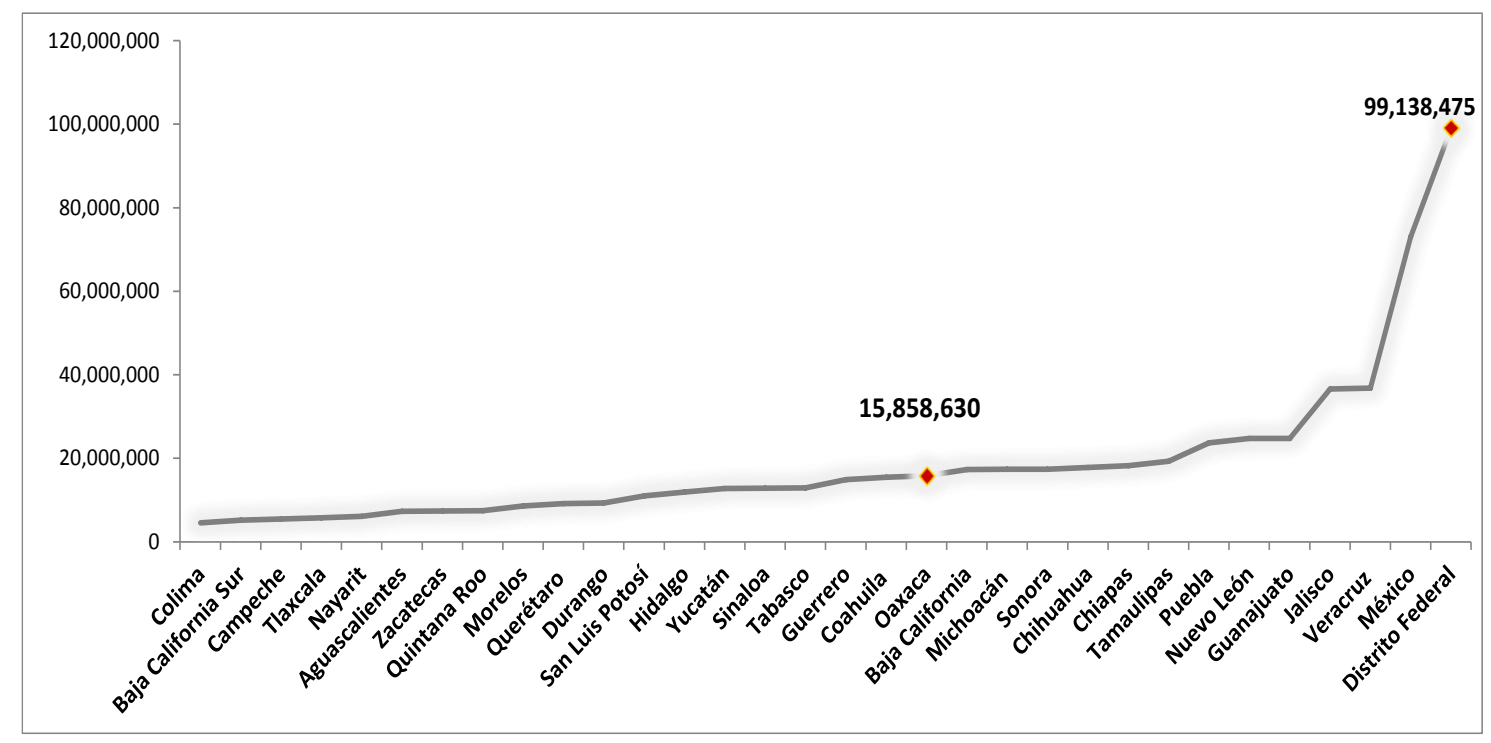

Figura 3. Gasto público total en Salud de 2017 (Miles de pesos corrientes). Fuente: Secretaría de Salud. Fuente de Financiamiento, 1993-2017. Base de Datos por Entidad Federativa. (Este gasto público es igual al Gasto Público en Salud para la Población con Seguridad Social más el Gasto Público en Salud para la Población sin Seguridad Social.

Para el gobierno local, las transferencias federales son de suma importancia para garantizar servicios de salud de calidad y para afrontar los niveles de gasto para la población sin seguridad social, la aportación federal al financiamiento de la salud para esta población es de más del 97\%, en 2017 fue el 99.4\% (SS, 2019). Como se observa en la figura 2 de este mismo documento, el gobierno federal transfiere recursos por concepto de cuota social y aportación solidaria federal, y se hace mediante un Acuerdo de Coordinación con la Secretaría de Salud y el Estado Oaxaca, mismo que es publicado en el Diario Oficial de la Federación, para el gasto de 2019, dicho acuerdo se publicó el 21 de junio. (DOF, 2019).

La transferencia de recursos se realiza a las entidades federativas mediante depósitos en las cuentas que constituyan los Regímenes Estatales de Protección Social en Salud (REPSS) en la Tesorería de la Federación (TESOFE), o en especie, con base en los Lineamientos para la transferencia de los recursos federales correspondientes al seguro popular, emitidos por la Secretaría de Salud (SS) y la Secretaría de Hacienda y Crédito Público (SHCP). De estos recursos los estados podrán usar hasta el $40 \%$ para remuneraciones de trabajadores ya contratados; de los cuales $20 \%$ serán de la rama administrativa y $80 \%$ de la rama médica. El $30 \%$ de estas transferencias será para la adquisición de medicamentos, materiales de curación y otros insumos para atender los servicios del CAUSES y de estos recursos el Estado podrá destinar el 5\% para subrogar la adquisición de medicamentos, bajo su responsabilidad de cumplir con las normas. El $20 \%$ más de los recursos se destinará para acciones de promoción, prevención y atención oportuna de enfermedades contenidas en el CAUSES. Hasta el 6\% en gasto operativo y el resto en acreditaciones de las unidades prestadoras de salud (Segob-Oaxaca, 2019).

De enero a julio de 2019, se transfirió a Oaxaca por cuota social la cantidad de $\$ 948$, 930,171 pesos y de la aportación solidaria $\$ 190,336,817$; por lo que corresponde al $30 \%$ 
para medicamentos el monto fue de $\$ 341,780,096$ pesos (CNPSS, 2019). Aun cuando las disposiciones normativas son muy detalladas para el manejo de estos recursos, se ha considerado por parte de la administración de López Obrador, que existe corrupción en la administración de dichos recursos y por ello las deficiencias en el sistema. Es una de las razones por las que se ha promovido su desaparición.

\subsection{Discriminación.}

Las condiciones de pobreza de Oaxaca convierten a su población en foco de discriminación. De ahí la importancia de analizar las posibles repercusiones derivadas de la transformación o desaparición del seguro popular en lugares como el aquí analizado. En esta entidad federativa, la estructura demográfica y la transición epidemiológica, consienten la correlación de enfermedades ligadas al rezago social (infecciones diarreicas, enfermedades respiratorias agudas, entre otras) con aquellas enfermedades crónicas degenerativas del desarrollo (diabetes, hipertensión, cáncer, obesidad, entre otras), vinculados a la presencia de fenómenos emergentes (sismos, huracanes e inundaciones) provocados por el cambio climático, esto revela una amplia gama de riesgos para la salud (Oaxaca, 2016).

Adicionalmente, las diferencias regionales en los niveles de vida, la pobreza y la desnutrición; la desigualdad educativa, el desempleo y la precariedad laboral, son determinantes para que se encuentre entre las entidades con menor Índice de Desarrollo Humano. A ello se agrega que sea la entidad con mayor diversidad de grupos indígenas, con $30.39 \%$ de su población y el $65.7 \%$ se auto-reconozca indígena (INEGI, 2015); que junto con Yucatán y Chiapas, acumulen el $42.6 \%$ de población hablante de una lengua indígena (Rizo Amézquita, 2017), con distintos hábitos y limitaciones para el cuidado alimenticio y condiciones higiénicas. En suma, Oaxaca está entre los 10 estados con mayores defunciones registradas por año.

El Coneval da cuenta de la situación con datos de la medición de pobreza y de carencias sociales (2008-2018), el 66.4\% de la población oaxaqueña vive en pobreza, sólo por encima de Guerrero y Chiapas; casi el $90 \%$ presenta por lo menos una carencia social y el $45 \%$ por lo menos tres, el $58.3 \%$ tiene problemas de acceso a los servicios básicos en la vivienda y, el 69\% cuenta con un ingreso inferior a la línea de pobreza. Si bien estos datos disminuyen durante el periodo de medición, la baja no ha sido consistente durante los últimos diez años, la educación y el acceso a la alimentación que son fundamentales para el desarrollo de las personas, presentan todavía porcentajes importantes $27.1 \%$ y $27.9 \%$ (en 2018) respectivamente, en comparación con el promedio nacional $16.9 \%$ en rezago educativo y $20.4 \%$ en alimentación (CONEVAL, 2019).

Contrario al principio de no discriminación para procurar el ejercicio del derecho a la salud, en esta entidad federativa se conjuntan motivos como el sexo (las mujeres padecen en gran medida falta de servicios de salud en el parto), el idioma, la religión, opinión política, origen social, posición económica, entre otros. 


\subsection{Afiliación}

Las carencias de acceso a la seguridad social, y la disponibilidad de los servicios de salud, ponen recurrentemente en riesgo a la población. En relación con las primeras, es claro que en tanto las actividades terciarias o de servicios sean las que predominan en Oaxaca (68.5\%), las condiciones de empleo no permiten la estabilidad laboral al 78\% (3,116.6 millones) de la población que no es acreedora del derecho a la seguridad social. Ello ha obligado al gobierno a brindarles acceso a los servicios de salud conforme a las reglas del seguro popular, lo que pareciera ha contribuido a reducir durante el periodo de diez años esta carencia, al pasar de más de dos millones a poco más de medio millón de habitantes que todavía la padecen, principalmente como se ha dicho, por las condiciones geográficas del estado y por otras propias adjudicadas a los gobiernos estatal y municipal (figura 4).

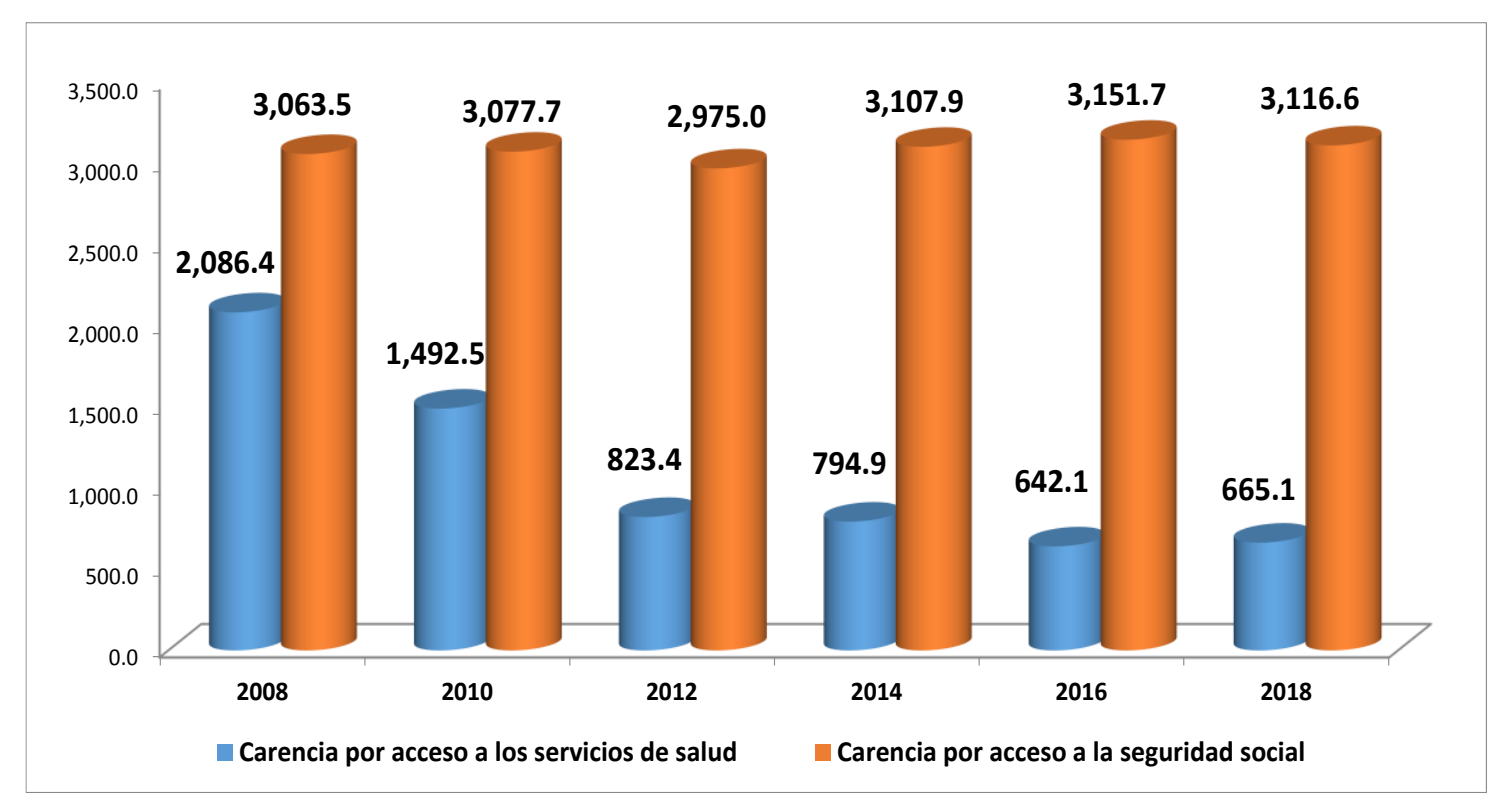

Figura 4. Carencias por acceso a los servicios salud y de seguridad social. Fuente: Elaboración propia con datos del Coneval, 2019.

Lo anterior justifica el gran número de afiliados al seguro popular, 2, 637,811 (66\%) millones de personas durante 2018 (figura 5), de estos, el $81.7 \%$ se ubica en el decil I, $17.2 \%$ en el II; $.09 \%$ en el III y $01 \%$ en el IV, en los deciles V al X se ubican el $0.03 \%$ (706 afiliados). 


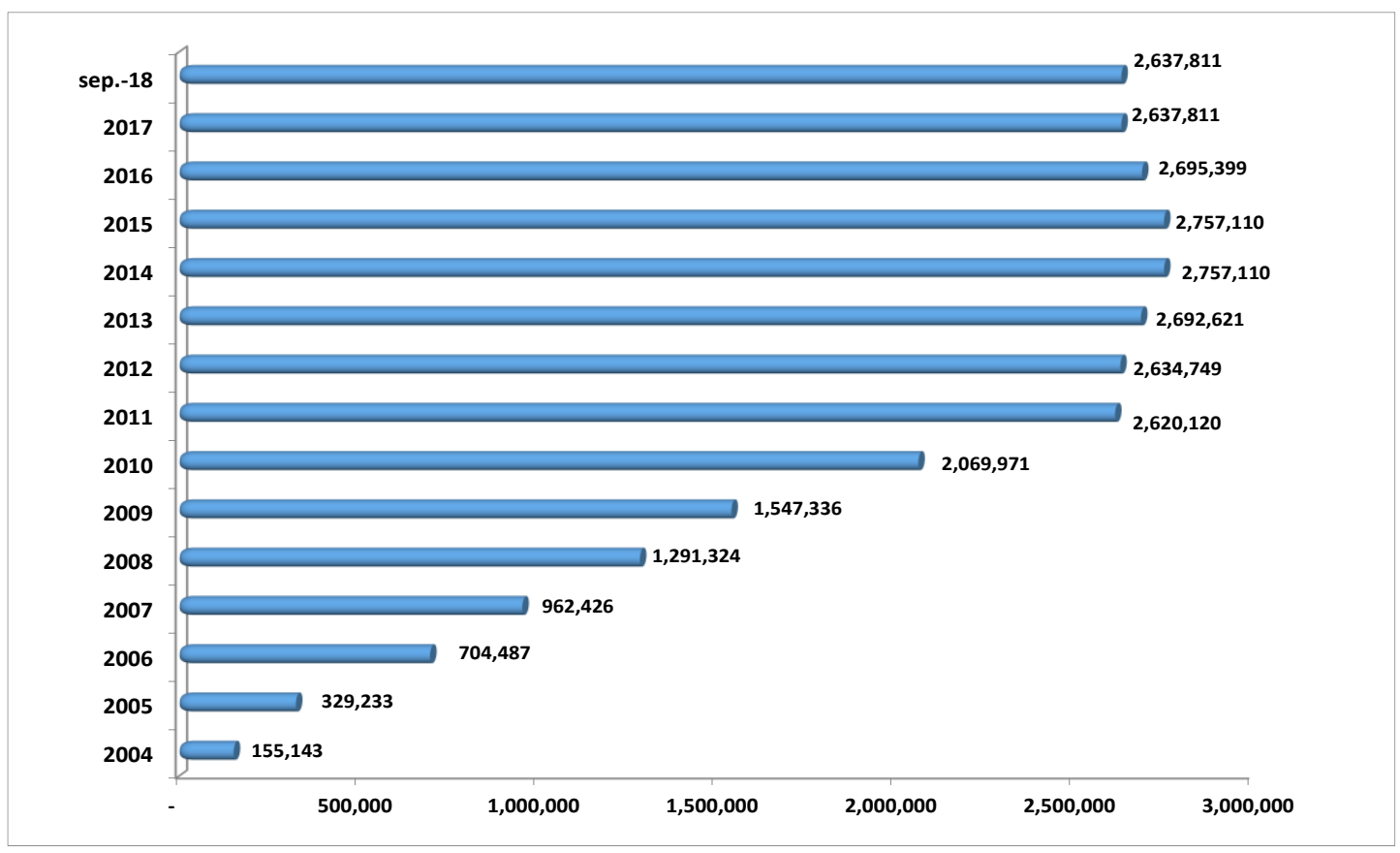

Figura 5. Afiliados al Seguro Popular, 2004-2018 Fuente: Elaboración propia con datos de INEGI-SPSS, 2018.

Según los datos del INEGI, en 2015 el seguro popular tuvo la afiliación más alta tanto a nivel nacional como en Oaxaca con $78.3 \%$, en comparación con los derechohabientes registrados en el IMSS (14.6\%) o ISSSTE (7\%), y en menor medida al resto de los sistemas. La voluminosa afiliación se refleja en población usuaria de los servicios de salud $(79.1 \%)$, aunque, según la figura 6, también las instituciones privadas tienen una contribución relevante $(77.1 \%)$ en la prestación de los servicios de salud (INEGI, 2015).

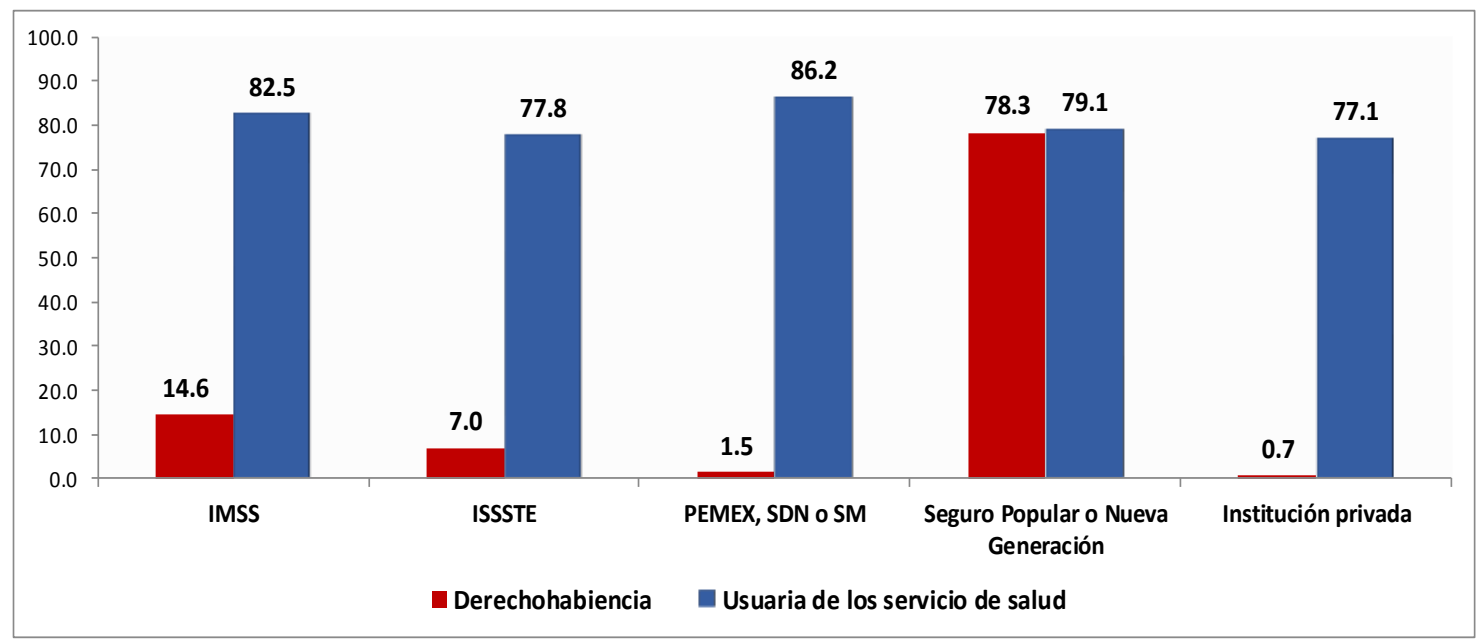

Figura 6. Porcentaje de distribución de derechohabiencia en Oaxaca. Fuente: Elaboración propia con datos del INEGI, 2015.

En Oaxaca los servicios privados son costosos en el caso de especialidades (como ginecología, pediatría, cardiología, entre otras), sobre todo en la ciudad, o muy accesible si se trata del primer nivel de atención, como el sistema de las farmacias "Similares" o 
del "Ahorro", que prestan el servicio de consulta médica con precios muy "bajos" (entre 20.00 y 50.00 pesos), aunque los "medicamentos similares" o "genéricos intercambiables" recetados, podrían tener eficacia terapéutica distinta con los originales (Domingu (Delgado, 2019)ez \& Pérez, 2009). Se adiciona a estos servicios lo que la Organización Mundial de la Salud define como medicina tradicional: "conocimientos, aptitudes y prácticas basados en teorías, creencias y experiencias indígenas de las diferentes culturas, sean o no explicables, usados para el mantenimiento de la salud, así como para la prevención, el diagnóstico, la mejora o el tratamiento de enfermedades físicas o mentales", esto incluye plantas, minerales y animales entre otros y que principalmente la población indígena acude a ésta de forma complementaria.

Al haber una mayor afiliación al seguro popular en 2015, el gasto público en salud per cápita se incrementó tanto a nivel nacional (7.8\%) como en Oaxaca (14.3\%) en relación con el año anterior, lo destacado aquí es que en la entidad los porcentajes de crecimiento son mayores en todos años. Como se observa en la figura 7, en 2017 ascendió este gasto a \$3,905 pesos en relación con los \$ 5,043 en la República mexicana (Salud, 1990-2017)

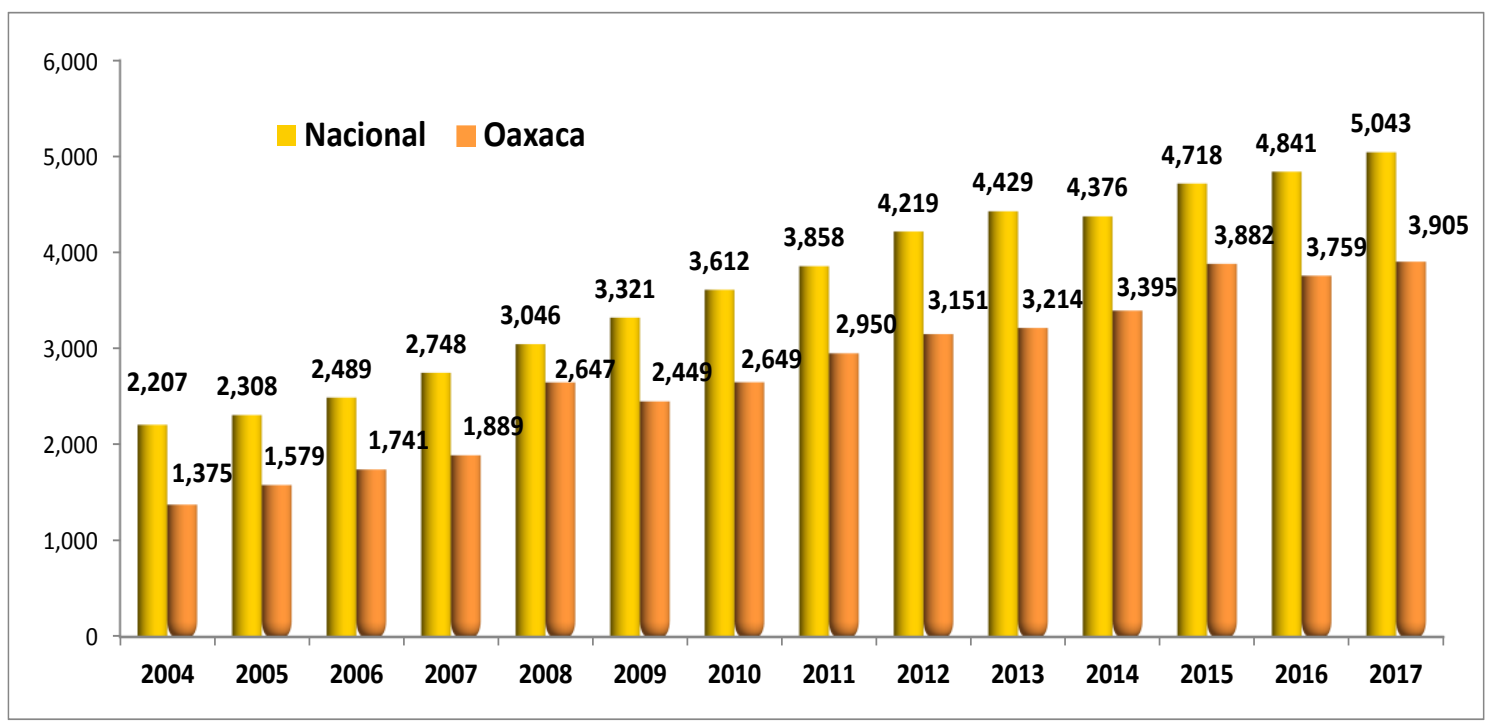

Figura 7. Porcentaje de distribución de derechohabiencia en Oaxaca. Fuente: Elaboración propia con datos del INEGI, 2015.

En especial, el gobierno federal actual pretende atender de forma importante a las comunidades indígenas, y se ha asignado para 2020 un monto de $\$ 5,689,605,218$ pesos en el rubro de "Erogaciones para el Desarrollo Integral de los Pueblos y Comunidades Indígenas. Seguro Popular”, de los que una parte corresponderá a Oaxaca.

Calidad

No obstante que las autoridades oaxaqueñas se han pronunciado porque la cobertura en salud no sólo signifique la afiliación de la población al seguro popular, sino que cada uno de los nuevos afiliados tenga acceso efectivo a los bienes y servicios de salud, existen limitaciones para que así sea en términos presupuestas, pero además, las claves de enfermedades amparadas por dicho seguro en la entidad federativa, en comparación con las registradas en la CIE-10, como ya se señaló antes, son mucho menores. Ello se 
reconoce con el pronunciamiento de las autoridades cuando se firmó el Convenio entre la Secretaría de Desarrollo, Social y Humano (Sedesoh) y la Dirección General del Régimen de Protección Social en Salud del Estado de Oaxaca (REPSS), que declararon: "Estamos haciendo equipo para que el seguro popular pueda llegar a cada uno de los municipios del estado y pueda beneficiar todos los días a más y más oaxaqueños que lo necesitan... ", indicaron además, que con esta acción "se avala la cobertura en salud de más de mil enfermedades" a través de la cartera del Causes, y se protege a los niños menores de cinco años con la cartera del Seguro Médico Siglo XXI, así como la cobertura de enfermedades de alto impacto y de alto costo a través de la cartera del FPCGC. (SEDESOH-REPSS, 2019).

En cuanto a datos municipales, el $55 \%$ de la población total de la entidad federativa se concentra en 30 municipios, mismos que se presentan en la figura 8; en estos, el $35 \%$ (928.112) están afiliados al Seguro Popular (55\% son mujeres y 45\% hombres). De los mismos, en dos el 100\% de la población está afiliada; en 7 municipios entre el 98 y $80 \%$; en 9 entre $77 \%$ y $61 \%$ y en 12 municipios entre el 59 y $31 \%$ pertenecen al sistema (CNPSS, 2018).

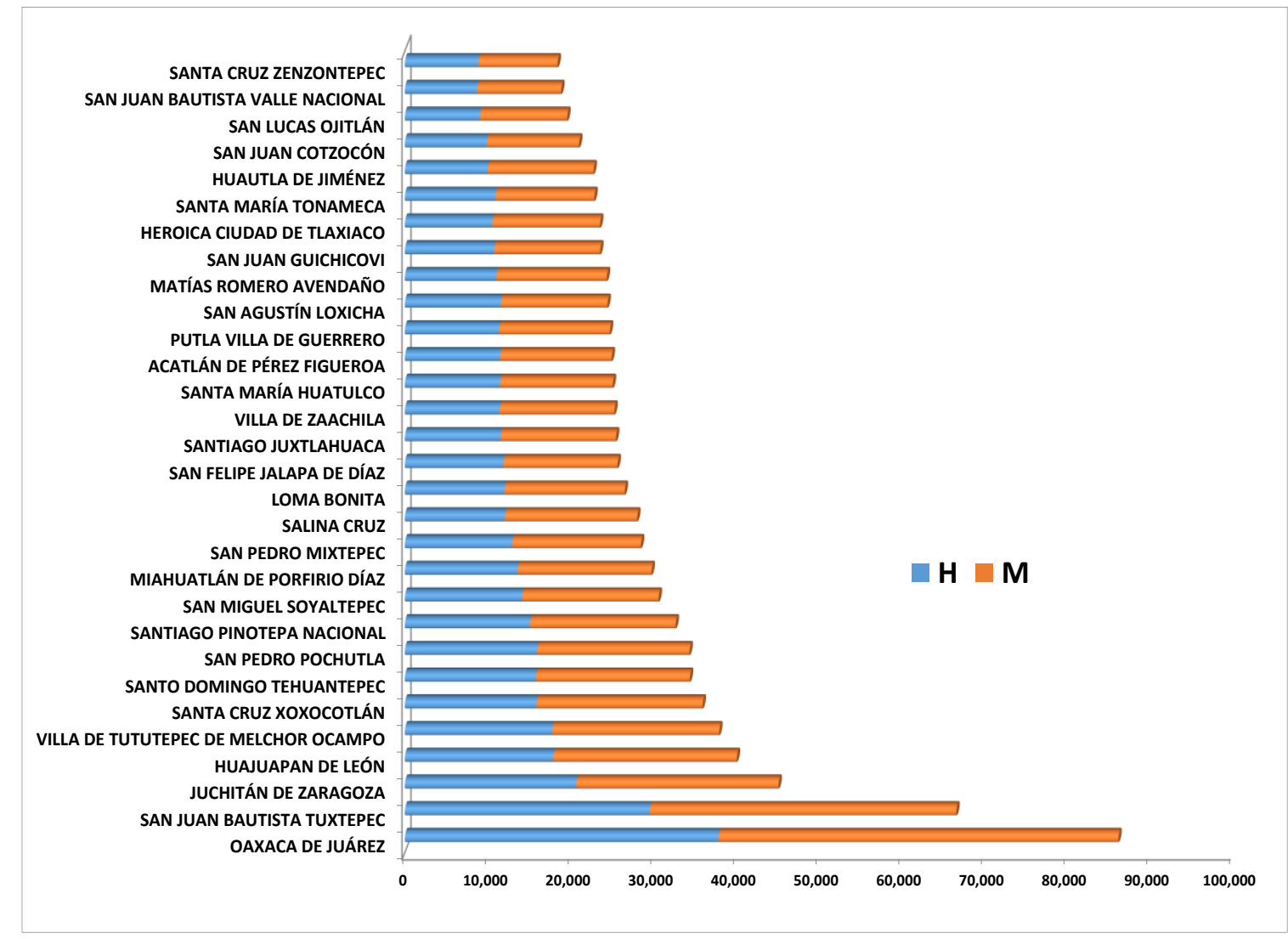

Figura 8. Porcentaje de afiliación al Seguro Popular, septiembre de 2018.Fuente: Elaboración propia con datos del INEGI-CNPSS, 2018. 


\subsection{Disponibilidad.}

Asimismo, cabe referir que en el resto de los municipios (540), cuya población es menor de 25,000 habitantes que viven en localidades generalmente dispersas en zonas rurales de difícil acceso, con falta de disponibilidad asistencial cuando la clínica local no se encuentra en servicio o no cuenta con los medios o infraestructura requeridos, aun así, la mayoría está afiliada al Seguro Popular, principalmente las mujeres. Estas condiciones son las que regularmente propician los gastos de bolsillo, ya que en situaciones de urgencia implica salir del municipio y recurrir a instancias de atención públicas o privadas (Hersch \& Rodríguez, 2017). Por ello, estar afiliado al sistema no ha sido suficiente para ejercer el derecho de acceso a los servicios de salud de manera efectiva, esto es, recibir servicios de calidad y cobertura universal para garantizar la atención equitativa, pero además, promover el cuidado de la salud, la prevención y el tratamiento de patologías.

Después de quince años del seguro popular en Oaxaca, las principales causas de morbilidad atendidas siguen siendo las enfermedades infecciosas como las respiratorias agudas, intestinales, de vías urinarias y conjuntivitis, que en suma representan el $78 \%$ de la demanda de los servicios de consulta ambulatoria (Oaxaca, 2016). Respecto a las enfermedades crónicas degenerativas como la diabetes mellitus, hipertensión arterial y obesidad, han presentado un incremento importante en los últimos 10 años, siendo la primera, junto con los tumores malignos y las enfermedades del corazón, los padecimientos que causan el mayor número de decesos, así como mayores gastos catastróficos para las familias, por hospitalizaciones, consultas, traslados y estancias de cuidadores, entre otros (Hersch \& Rodríguez, 2017).

Las propias autoridades de Oaxaca reconocen que, conforme a las normas técnicas nacionales, aun se tiene baja cobertura en la prevención y detección, lo que dificulta el control de estos padecimientos, con la presencia temprana de sus complicaciones y los consecuentes incrementos en los costos de su atención y en la calidad de vida de los pacientes (Oaxaca, 2016).

Es por ello que lograr una cobertura universal de salud en este estado sigue siendo una labor compleja por su diversidad geográfica, económica, social y cultural, en virtud de que casi la mitad de los municipios (47\%) cuenta con menos de dos mil habitantes y muchas localidades con menos de mil, lo cual obstaculiza la distribución de los recursos y propicia el desequilibrio de la atención. Estar afiliados al Seguro Popular puede ser una ventaja, pero poder ejercer el derecho a los servicios de salud de forma oportuna es un suplicio para muchas familias; desde llegar a una clínica comunitaria para atender problemas de salud de enfermedades infecciosas, hasta lograr ingresar a un hospital de tercer nivel para atender enfermedades graves crónicas degenerativas, o llevar un tratamiento en caso de tumores malignos o distintos tipos de cáncer. Oaxaca se encuentra entre las 12 entidades federativas que más egresos hospitalarios tienen con 61,071 eventos durante 2018, del total en la República Mexicana 1, 735,350 (CNPSS, 2019). 


\section{Comentarios finales.}

La salud es un derecho humano, cuya exigibilidad se sustenta en un andamiaje jurídico amplio tanto a nivel nacional como internacional, y no puede quedar a expensar sólo en términos presupuestarios. Una de las principales estrategias de financiamiento para afrontar los gastos en salud en las últimas décadas fue la implementación del seguro popular desde 2003, cuyo fin era brindar protección financiera a todos los mexicanos y contribuir reducir gastos de bolsillo de las familias de la población abierta principalmente.

Durante décadas los gobiernos en México han establecido distintos programas y estrategias para afrontar el reto de la cobertura universal y se han propuesto metas sexenales que por lo regular no son alcanzadas en la realidad, aunque en sus informes se registren ciertos logros, como ha sido en la última administración de 2012-2018, que se dejó de hacer lo que era posible, administrar adecuadamente los recursos escasos.

Tan no se protegió y garantizó este derecho social a nivel nacional, que los datos sobre la carencia por acceso a los servicios de salud son todavía significativos y ha sido inconsistente su reducción, e incluso se incrementó el porcentaje de la población que la padece de 2016 a 2018, al pasar de 15.5 a 16.2\%, peor aún la carencia de seguridad social que pasó de 55.8 a $57.3 \%$ durante el mismo periodo (CONEVAL, 2019).

Por ello, el presidente de la República (2018-2024), ha referido en múltiples ocasiones que el seguro popular ni es "seguro, ni es popular", argumentando su desaparición y sustitución por otro sistema de cobertura universal. En el Plan Nacional de esta administración se indica que el "gobierno federal realizará las acciones necesarias para garantizar que hacia 2024 todas y todos los habitantes de México puedan recibir atención médica y hospitalaria gratuita, incluidos el suministro de medicamentos y materiales de curación y los exámenes clínicos” (República, 2019).

Sin embargo, su propuesta de crear un Instituto de Bienestar para la Salud, mediante la reforma a la Ley General de Salud presentada por el partido que lo llevó al poder, y el reemplazo del seguro popular es todavía incipiente, el modelo propuesto será de atención primaria de la salud, en la que la persona y la comunidad pueden tomar decisiones y tener un papel activo sobre la salud. El problema es mucho más complejo, la población mexicana está envejeciendo y con ello se presentan enfermedades crónicas degenerativas que deberán tener un financiamiento y trato especiales.

Se esperaría que efectivamente esta decisión fortalezca el entramado institucional que ya existe en materia de control y evaluación de los recursos públicos para la salud, que comprende a la propia SHCP, CONEVAL, el órgano interno de control de la SS, así como la Auditoría Superior de la Federación o de las instituciones académicas que han señalado en su momento, las fortalezas y debilidades de la política.

En el caso específico de Oaxaca, como se ha revisado, las transferencias del gobierno federal son fundamentales para atender a la mayoría de la población abierta que vive con graves problemas de pobreza; y con graves carencias en distintas áreas de la salud, la alimentación, la vivienda y sobre todo el acceso a la seguridad social generada por la 
inestabilidad laboral en la que se encuentran los oaxaqueños para afrontar gastos catastróficos y de bolsillo en salud.

En realidad, y visto desde el enfoque de los derechos humanos, en Oaxaca predomina la discriminación, la no disponibilidad adecuada, lo que dificulta el acceso, aun cuando exista la afiliación, se ha puesto en duda la aceptabilidad de los establecimientos, así como su calidad y la rendición de cuentas. Finalmente, si la decisión gubernamental de la desaparición del seguro popular a partir de 2019, no es sólo política, y materializa la universalidad en Oaxaca, podría garantizar el derecho a la salud de forma efectiva, pero esta debe ser desde el enfoque del derecho a la salud: no discriminación, disponible, accesible tomando en cuenta los principios de aceptabilidad, calidad y rendición de cuentas.

\section{Bibliografia}

CANO VALLE, Fernando, Derecho a la protección a la salud en América Latina. México, D.F., UNAM-UNESCO, 2010, disponible en

https://archivos.juridicas.unam.mx/www/bjv/libros/6/2896/1.pdf [consulta: 2 de junio de 2019].

CARMONA TINOCO, Jorge Ulises, "La reforma y las normas de derechos humanos previstas en los tratados internacionales", en CARBONELL SÁNCHEZ, Miguel y SALAZAR UGARTE, Pedro, La Reforma Constitucional de Derechos Humanos. Un nuevo paradigma, México, D.F., UNAM-IIJ, 2011, disponible en https://archivos.juridicas.unam.mx/www/bjv/libros/7/3033/4.pdf [consulta: junio 2011], pp. 39-62.

DELGADO CARRILLO, Mario, Iniciativa con proyecto de decreto por el que se reforman, adicionan y derogan diversas disposiciones de la Ley General de Salud, Gaceta de la Comisión Permanente. 03 de julio de 2019, disponible en https://infosen.senado.gob.mx/sgsp/gaceta/64/1/2019-07-031/assets/documentos/Ini_Delgado.pdf

https://www.senado.gob.mx/64/gaceta_comision_permanente/documento/97154 [consulta: 04 de julio de 2019].

DOMINGUEZ PÉREZ, David Alfredo y PÉREZ RUL, María Natalia, "Los medicamentos similares ¿una nueva clase de medicina o sólo la estrategia comercial?” Revista Mundo Siglo XXI, $2009 \quad \mathrm{n}^{\circ}$ 18, disponible en: https://biblat.unam.mx/hevila/MundosigloXXI/2009/no18/7.pdf $\quad$ [consulta: 10 de diciembre 2019], pp. 77-86.

FRENK MORA, Julio, El Sistema de Salud: ¿Reforma o Regresión? en FRENK MORA, Julio, SOBERÓN ACEVEDO, Guillermo y PEREZ TAMAYO, Ruy (coords) La encrucijada de la salud, Mesa. 3er Encuentro Libertad por el saber. México, El Colegio 
Nacional. 14 diciembre de 2018, disponible en https://www.youtube.com/watch?v=T2aTN_kcaA8 [consulta: 20 de junio de 2019].

FRENK MORA, Julio, Proteger a México. Un enfoque integral para que el gobierno no nos falle, México. Editores Cal y Arena y El Colegio Nacional, 2019.

HERNÁNDEZ, ÁVILA, Mauricio, et. altri, Salud deteriorada. Opacidad y negligencia en el sistema público de salud, Ciudad de México, Mexicanos contra la Corrupción y la Impunidad, 2018, disponible en https://saluddeteriorada.contralacorrupcion.mx/wpcontent/uploads/pdf/SD-Completo.pdf [consulta: septiembre de 2019].

HERSCH-MARTÍNEZ, Paul y RODRÍGUEZ-HERNÁNDEZ, Berenice, “Un marcador epidemiológico invisibilizado: el endeudamiento en una población afromexicana de Oaxaca”. Salud Pública en México, marzo-abril de 2017, $\mathrm{n}^{\circ}$ 2, volumen 59, disponible en http://www.scielo.org.mx/scielo.php?script=sci_arttext\&pid=S0036-

36342017000200193 [consulta: 15 de agosto de 2019], pp. 193-201.

LAURELL, Asa Cristina, Impacto del seguro popular en el sistema de salud mexicano. México Colección CLACSO-CROP, 2013, disponible en file://C:/Users/Dell/Downloads/LAURELL-Impacto\%20del\%20seguro\%20popular.pdf [consulta: 28 de septiembre de 2019].

MORENO, Alejandro, "AMLO llega con 67\% de aprobación a su Primer Informe”, El Financiero, 30 de agosto de 2019, disponible en https://www.elfinanciero.com.mx/nacional/amlo-llega-con-67-de-aprobacion-a-suprimer-informe [consulta: 30 de agosto de 2019].

MUÑOZ, Alma E. "Instituto del Bienestar remplazará al Seguro Popular, anuncia AMLO”, La Jornada, 12 de julio de 2019, disponible en https://www.jornada.com.mx/ultimas/politica/2019/07/12/Instituto-del-bienestarremplazara-al-seguro-popular-anuncia-amlo-7203.html, [consulta: 12 de julio de 2019]. RIZO AMÉZQUITA, José, Población indígena en cifras, Boletín CONAMED-OPS, $\mathrm{n}^{\circ}$ 13, julio-agosto 2017, en http://www.conamed.gob.mx/gobmx/boletin/pdf/boletin13/poblacion_indigena.pdf [consulta: 13 de marzo de 2019].

\section{Anexo: normas, informes y estudios}

CESCR, General Comment No. 20 Non-discrimination in economic, social and cultural rights (art. 2, para. 2, of the International Covenant on Economic, Social and Cultural Rights), 02 de julio de 2009, Committee on Economic, Social and Cultural Rights, disponible en https://digitallibrary.un.org/record/659980 [consulta: 03 de marzo de 2019].

CNPSS. Informe de Resultados del Sistema de Protección Social de Salud. Comisión Nacional de Protección del Sistema de Salud, enero-junio de 2019, disponible en: http://www.transparencia.seguro- 
popular.gob.mx/contenidos/archivos/transparencia/planesprogramaseinformes/informes/ 2018/InformedeResultadosdelSPSSenero_junio2019.pdf [consulta: 19 de octubre de 2019].

CNPSS, Información general del Sistema Nacional de Protección Social en Salud. Comisión Nacional de Protección Social de Salud, s/f, Seguro Popular, disponible en http://www.salud.gob.mx/transparencia/inform_adicional/InfoGralSP.pdf [consulta: 19 de agosto de 2019].

CNPSS, Informe de Resultados del Sistema de Protección Social en Salud enero-junio 2019, Comisión Nacional de Protección Social en Salud, 2019, disponible en http://www.transparencia.seguro-

popular.gob.mx/contenidos/archivos/transparencia/planesprogramaseinformes/informes/ 2018/InformedeResultadosdelSPSSenero_junio2019.pdf [consulta 29 de noviembre de 2019].

CNPSS, Beneficiarios del Sistema de Protección Social en Salud por municipio. Comisión Nacional de Protección Social en Salud. Seguro Popular, 2018, disponible en https://datos.gob.mx/busca/dataset/beneficiarios-de-proteccion-social-en-salud-deseguro-popular [última consulta junio de 2019].

CONEVAL, Estudio Diagnóstico del Derecho a la Salud. México: Consejo Nacional de Evaluación de la Política de Desarrollo Social, 2018, disponible en https://www.coneval.org.mx/Evaluacion/IEPSM/Documents/Derechos_Sociales/Diag_d erecho_Salud_2018.pdf [consulta:12 de junio de 2019].

CONEVAL, Medición de la pobreza 2008-2018, Consejo Nacional de Evaluación de la Política de Desarrollo Social, agosto de 2019, disponible en https://www.coneval.org.mx/Medicion/Paginas/PobrezaInicio.aspx [consulta: agosto 2019].

DIARIO OFICIAL DE LA FEDERACIÓN, Ley General de Salud, México: Cámara de Diputados del H. Congreso de la Unión, 12 de julio de 2018, disponible en http://www.diputados.gob.mx/LeyesBiblio/pdf/142_240120.pdf [última consulta: 18 de noviembre de 2019].

DIARIO OFICIAL DE LA FEDERACIÓN , Plan Nacional de Desarrollo 2001-2006, Presidencia de la República, Gobierno de México, 30 de mayo de 2001, disponible en http://dof.gob.mx/nota_detalle.php?codigo=766335\&fecha=30/05/2001 [última consulta: 20 de mayo de 2019].

DIARIO OFICIAL DE LA FEDERACIÓN, Plan Nacional de Desarrollo 2019-2024, Presidencia de la República Gobierno de México, 12 de julio de 2019, disponible en https://www.dof.gob.mx/nota_detalle.php?codigo=5565599\&fecha=12/07/2019 [consulta:14 de julio de 2019].

DIARIO OFICIAL DE LA FEDERACIÓN, ANEXO IV Conceptos de Gasto 2019 del Acuerdo de Coordinación para la ejecución del Sistema de Protección Social en Salud, que celebran la Secretaría de Salud y el Estado de Oaxaca, Secretaría de Salud y 
Comisión Nacional de Protección Social en Salud, Seguro Popular, 21 de junio de 2019, disponible en https://dof.gob.mx/nota_detalle.php?codigo=5563830\&fecha=21/06/2019 [consulta: 17 de agosto de 2019

GOBIERNO DE OAXACA, Plan Estratégico Sectorial de Salud, 2016-2022. Obtenido de Secretaría de Salud. Servicios de Salud de Oaxaca: https://www.oaxaca.gob.mx/salud/plan-estrategico-sectorial-salud-2016-2022/ [última consulta: 20 de enero de 2019].

INEGI, Encuesta Intercensal 2015, Instituto Nacional de Estadística y Geografía, 2015, disponible en: https://www.inegi.org.mx/programas/intercensal/2015/ [última consulta: 28 de agosto de 2019].

OCDE, Estudios de la OCDE sobre los sistemas de salud: México, México, Organización para la Cooperación y el Desarrollo Económico 2016, disponible en https://www.oecd.org/health/health-systems/OECD-Reviews-of-Health-Systems-

Mexico-2016-Assessment-and-recommendations-Spanish.pdf [consulta: 14 de junio de 2019].

OIT-OPS, Panorama de la exclusión de la protección social en salud en América Latina y el Caribe. México, Organización Internacional del Trabajo y Organización Panamericana de la Salud, 1999, disponible en: http://www.oitopsmexico99.org.pe [consulta 26 de septiembre de 2019].

OMS, Salud y Derechos Humanos, 29 de diciembre de 2017, Organización Mundial de la Salud, disponible en https://www.who.int/es/news-room/fact-sheets/detail/humanrights-and-health [consulta: 5 de agosto de 2019].

SEDESOH-REPSS, Garantizan acceso a la salud de las y los oaxaqueños, Secretaría de Desarrollo Social y Humano y la Representación Estatal del Seguro Popular, 27 de marzo de 2019, disponible en https://www.oaxaca.gob.mx/sedesoh/2019/04/04/sedesoh-yseguro-popular-garantizan-acceso-a-la-salud-de-las-y-los-oaxaquenos/ [consulta: 29 de marzo de 2019].

SS, Gasto en Salud en el Sistema Nacional de Salud. Gasto en Salud, por Fuente de Financiamiento y Entidad Federativa, 1990 a 2017, Secretaría de Salud, 09 de mayo de 2019 disponible

en http://www.dgis.salud.gob.mx/contenidos/sinais/gastoensalud_gobmx.html [última consulta: 15 de junio de 2019].

SS, Programa Nacional de Salud 2001-2006. México, Secretaría de Salud, 2001, disponible en http://www.salud.gob.mx/unidades/evaluacion/publicaciones/pns_20012006/pns2001-006.pdf [última consulta 13 de junio de 2019].

SS y SP, Sistema de Protección Social en Salud. Elementos conceptuales, financieros y operativos. México, D.F.: Secretaría de Salud y Seguro Popular, 2005, disponible en http://www.salud.gob.mx/unidades/cdi/documentos/DOCSAL7723.pdf [última consulta: 25 de enero de 2019]. 
WHO, OECD, WB, Delivering quality health services: a global imperative for universal health coverage, Organization Economic for Cooperation and Development, and International Bank for Reconstruction and Development/The World Bank, 2018, disponible en

http://documents.worldbank.org/curated/en/482771530290792652/pdf/127816-

REVISED-quality-joint-publication-July2018-Complete-vignettes-ebook-L.pdf [consulta: 15 de abril de 2019]. 